\title{
Faktor-faktor yang mempengaruhi perilaku bullying
}

\author{
Pipih Muhopilah \\ Magister Psikologi, Program Pascasarjana, Universitas Ahmad Dahlan \\ pipihmuhopilah7@gmail.com \\ Fatwa Tentama \\ Magister Psikologi, Program Pascasarjana, Universitas Ahmad Dahlan \\ fatwa.tentama@psy.uad.ac.id
}

\begin{abstract}
ABSTRAK
Bullying merupakan perilaku agresif di sengaja dengan tujuan untuk memberikan gangguan fisik maupun psikologis pada orang lain. Fenomena bullying yang terjadi di berbagai belahan dunia dapat menimbulkan berbagai efek negatif, baik bagi korban maupun bagi pelaku. Penelitian ini bertujuan untuk melakukan kajian literatur mengenai fakor-faktor yang mempengaruhi perilaku bullying. Penelusuran dilakukan di database elektronik seperti Proquest, Science Direct, Scopus dan Google Schoolar dengan menggunakan kata kunci "bullying" dengan tahun terbit artikel antara tahun 2014 sampai 2019. Hasil review literatur menunjukan bahwa faktor-faktor yang mempengaruhi perilkau bullying yaitu kepribadian, keluarga, adverse children experience dan lingkungan sekolah. Penelitian mengenai bullying mayoritas di lakukan pada remaja dengan ruang lingkup penelitian di sekolah. Skala penelitian yang digunakan di dasarkan pada bentuk-bentuk penelitian yang disusun oleh Olweous.
\end{abstract}

Kata Kunci :Bullying, Keluarga, Kepribadian, Sekolah

\begin{abstract}
Bullying is aggressive behavior which done to intentionally with the aim is to provide physical and psychological disorder to others. The phenomenon of bullying that occurs in various parts of the world can have a variety of negative effects, both for victims and for perpetrators. Searches were carried out in the Proquest, Science Direct, Scopus and Google Schoolar electronic databases using the keyword "bullying" with the year of the article was published between 2014 until 2019. The literature review results show that the factors that influence bullying behavior are personality, family, adverse children experience and schoolenvironment. the majority of bullying research is conducted on adolescents, the research space in schools and the scale of research used is based on the forms of research compiled by Olweous.
\end{abstract}

Keywords : Bullying, Family, Personality, School

\section{PENDAHULUAN}

Survey yang dilakukan UNESCO pada tahun 2018 menunjukan bahwa bullying terjadi di berbagai negara dengan persentase terendah $7 \%$ di Tajikistan dan tertinggi $74 \%$ di Samoa (http://uis.unesco.org). Di Indonesia, Komisi Perlindungan Anak Indonesia (KPAI) mencatat terjadi sebanyak 253 kasus bullying pada tahun 2011 sampai 2016 (Nuridha, 2017). Data dari KPAI yang dirilis 
Jurnal Psikologi Terapan dan Pendidikan

ISSN: $2715-2456$

Vol. 1, No. 2, November 2019, pp. 99-107

kembali pada 23 Juli 2018 menunjukan bahwa sampai Mei 2018 terjadi 36 kasus bullying, yang jika di presentasikan merupakan 22,4\% dari 161 kasus yang terdata di bidang pendidikan (Nurlita \& Widiastuti, 2018). Secara teoritis bullying merupakan suatu keadaan yang berupa perilaku negatif dan berulang, yaitu saat seseorang kesulitan untuk mempertahankan dirinya dari suatu kekuatan yang tidak seimbang, perlakuan tersebut dilakukan dengan sengaja dan intens. Seseorang menjadi pelaku bullying ketika mengarahkan perilaku negatif kepada seorang atau lebih secara berulang dan dalam waktu tertentu. Definisi tersebut mengandung tiga poin utama yaitu adanya perilaku negatif yang dilakukan dengan sengaja, adanya pengulangan bullying terhadap korban, dan adanya ketidakseimbangan kekuatan (baik secara fisik ataupun psikis) antara korban dan pelaku bullying (Olweus, 1993).

Fenomena bullying menjadi hal yang serius di bidang pendidikan. Bullying dapat berakibat negatif baik terhadap korban maupun pelakunya, keduanya dapat mengalami masalah jiwa dan sosial, bahkan sampai bunuh diri (Abdussalam, 2018). Bagi korban, efek negatif bullying dapat berupa efek jangka pendek seperti luka fisik, maupun efek jangka panjang seperti mengalami kecemasan, depresi, penggunaan zat berbahaya, peluang melakukan bullying pada orang lain serta memungkinkan munculnya berbagai gangguan perilaku lain (Smokowski \& Kopasz, 2005). Bullying dapat menimbulkan masalah pada aktivitas sosial, merasa takut untuk sekolah sehingga sering absen, tidak dapat belajar dengan baik dan tidak dapat berkonsentrasi yang kesemuanya dapat menimbulkan penurunan prestasi belajar (Ayu \& Rahayu, 2014). Perilaku bullying juga dapat memunculkan depresi, perilaku psikopatologi, masalah kesehatan serta perilaku menyakiti diri sendiri (Sung, Dorothy, Kaylor, \& Allen, 2011).

Pelaku bullying melakukan tindakan menyakiti orang lain ini secara sadar dan inisiatif, tanpa adanya provokasi dari korban. Korban bullying dapat berupa individu maupun kelompok (Careera, DePalma, \& Lamerias, 2011). Bagi pelaku, bullying dapat membuat penurunan empati (Wilford, Bouton, Bank, Bender, Dieterich \& Jenson, 2015), peningkatan perilaku agresif (Evans, Smokowski, Rose, Mercado, \& Marshal, 2018), terbiasa mendapatkan sesuatu dengan cara memaksa (Hawley, 2003), peningkatan perilaku anti sosial (Farrington \& Ttofi, 2011), tidak disukai teman-teman sehingga dapat menimbulkan perasaan negatif tentang masa depan (Bruyn, Cillessen, \& Wissink, 2010), serta berpotensi mengalami masalah kesehatan mental (Healy, Sanders, \& Lyer, 2015).

Berdasarkan latar belakang masalah yang telah di uraikan dan didukung dengan hasil penelitian terdahulu maka tujuan dari penelitian ini untuk mengetahui faktor-faktor yang mempengaruhi perilaku bullying. 


\section{METODE PENELITIAN}

Penelitian ini merupakan penelitian sistematic review dengan menggunakan metode kualitatif dengan teknik meta sintesis. Pendekatan yang digunakan dalam penelitian ini adalah pendekatan metaetnograf, yakni dengan merangkum berbagai hasil penelitian yang relevan secar anaratif agar dapat mengembangkan teori yang baru untuk melengkapi teori-teori sebelumnya. Penelusuran ini dilakukan pada tanggal 04 Agustus melalui database elektronik seperti Proquest (www.proquest.com), science direct(www.sciencedirect.com), Scopus (www.scopus.com) dan Google Schoolar (scholar.google.co.id) dengan menggunakan kata kunci bullying. Database elektronok tersebut menyediakan berbagai hasil penelitian, salah satunya penelitian-penelitian di bidang psikologi. Sumber data yang akan di analisis dibatasi mulai tahun 2014 hingga 2019.

\section{Kriteria Seleksi}

Berdasarkan hasil penelusuran yang telah dilakukan, peneliti melakukan penelaahan dengan membaca judul dan abstrak untuk mengetahui apakah artikel yang dibaca sudah memenuhi kriteria untuk dikaji. Kriteria yang digunakan yaitu: 1) artikel penelitian membahas tentang bullying; 2) artikel membahas tentang pengaruh variabel x terhadap bullying; 3) artikel berisi laporan hasil penelitian; 4) artikel ditulis dalam bahasa inggris. Peneliti memperoleh 25 artikel publikasi tetapi setelah diseleksi, hanya 10 artikel yang relevan untuk dikaji.

Analisis

Peneliti melakukan identifikasi, evaluasim dan interpretasi terhadap semua hasil penelitian yang relevan terkait dengan kepribadian hardiness. Tujuan penelitian ini untuk mengindentifikasi faktor-faktor yang mempengaruhi bullying. Peneliti mengumpulkan 10 rtikel publikasi yang relevan untuk dikaji dan membuat rangkuman hasil penelitian yang terdiri dari nama peneliti, tahun publikasi, jumlah subjek, alat ukur yang digunakan serta hasil penelitian. Berdasarkan hasil tersebut peneliti membuat kesimpulan mengenai faktor-faktor yang mempengaruhi bullying.

\section{HASIL}

Berdasarkan hasil analisis pada 10 artikel yang relevan untuk dikaji, diperileh hasil sebagai berikut:

\section{Kepribadian}

Kepribadian menjadi salah astu faktor yang mempengaruhi bullying. Kepribadian yang berasosiasi positif dengan bullying adalah kepribadian extraversion (Mazzone \& Camodeca, 2019). Hasil penelitian tersebut di dukung oleh penelitian Manesini, Nocentini dan Camodeca (2010) yang 
Jurnal Psikologi Terapan dan Pendidikan

ISSN: $2715-2456$

Vol. 1, No. 2, November 2019, pp. 99-107

menemukan bahwa pelaku bullying biasanya memiliki kepribadian ekstrovert. Mitsopoulo dan Giovazolias (2015) juga menemukan bahwa kepribadian extraversion berperan penting pada perilaku agresif dan anti sosial. Perilaku bullying cenderung dilakukan oleh individu yang memiliki tingkat neurotism dan extraversion tinggi dan rendah dalam agreebelness dan concientiousness (Angelis, Bacchini, \& Affuso, 2016; Mazzone \& Camodeca, 2019). Kepribadian extraversion memiliki asosiasi positif dengan perilaku bullying (Mazzone \& Camodeca, 2019).

Kepribadian lain yang mempengaruhi bullying adalah Callous-Unemotional Traits (Thronberg \& Jungert, 2017). Kepribadian ini dicirikan dengan karakter callousness (kurangnya empati dan keprihatinan terhadap kesejahteraan, bahaya dan penderitaan orang lain), uncaring (kurangnya keprihatinan tentang bagaimana anggapan orang lain terhadap seseorang di kehidupan sosial) serta unemotional (tidak terbuka dalam mengungkapkan atau mengekspresika perasaan pada seseorang) (Fanti, Frick, \& Georgiou, 2009). Bullying dapat dilakukan oleh individu dengan kepribadian ini karena individu dengan kepribadian tersebut tidak dapat menalar efek berbahaya dari apa yang dilakukannya (Thronberg \& Jungert, 2017).

\section{Keluarga}

Keluarga merupakan faktor yang penting bagi bullying, faktor keluarga yang mempengaruhi bullying diantaranya rendahnya fungsi keluarga (Mazzone \& Camodeca, 2019) dan pola asuh (Charalampous, Demetriou, Tricha, Ioannou, Georgiou, Nikiforou, \& Stavrinides, 2018). Pola asuh yang berpengaruh positif pada perilaku bullying adalah pola asuh otiriter (Bostari \& Karagianni, 2014), hal tersebut karena pola asuh otoriter ditunjukan dengan orangtua yang melakukan penghukuman, bentuk hukuman yang diberikan merupakan bentuk kekerasan fisik dan psikologis, melakukan kekerasan untuk menyelesaikan konflik sehingga anak mempresepsikan bahwa orangtuanya tidak sensitif terhadap perasaannya. Hal tersebut membuat anak tidak mampu mengembangkan empati terhadap orang lain serta lebih agresif pada teman sebaya (Georgiou, Stavrinides, \& fousiani, 2013). Anak dengan pola asuh otoriter cenderung tidak mampu untuk mengembangkan kepedulian terhadap lingkungan karena anak terbiasa untuk menerima hukuman secara fisik dari orangtua (Smith, 2004), sehingga membuat anak lebih beresiko melakukan bullying (Martinez, Murgui, Garcia \& Garcia, 2019). Pola asuh otoriter yang mendukung penggunaan hukuman sebagai upaya pendisiplinan anak juga meningkatkan resiko keterlibatan dalam perilaku bullying (Ortiz, Romera \& Ruiz, 2015).

Keluarga adalah tempat bagi anak untuk belajar berperilaku dan membina hubungan interpersonal. Hubungan anak dengan keluarga dapat memprediksi perilaku bullying (Malm \& Henrich, 2019). Pengalaman anak bersama keluarga dan pola asuh orangtua berperan untuk membentuk kapasitas anak 
dalam beradaptasi di sekolah dan berpengaruh pada hubungan anak dan teman sebayanya (Lereya, Samara, \& Wolke, 2013). Anak yang mengalami pengabaian dirumah mengalami perkembangan yang lebih buruk daripada anak yang tidak mengalami pengabaian (Chapple \& Vaske, 2010), penolakan dari ibu (Papadaki \& Giovazolias, 2013) dan kekerasan dirumah juga berpotensi untuk meningkatkan resiko perilaku bullying disekolah (Sung, Dorothy, Kaylor, \& Allen, 2011). Bullying juga sering dihubungkan dengan pola attachment keluarga yang buruk, tidak adanya kepercayaan pada orangtua, serta buruknya lingkungan keluarga.Selian itu orangtua yang attachmennya rendah menyababkan anak lebih berpotensi untuk melakukan bullying (Murphy, Laible, \& Augustine, 2017).

\section{Adverse children experience (pengalaman buruk di masa kecil)}

Adverse children experience menjadi salah satu faktor yang mempengaruhi bullying. Siswa yang terlibat dalam bullying sangat mungkin adalah siswa yang mengalami berbagai kesulitan pada masa anakanak, kesulitan yang dialami anak membuat perkembangan psikologisnya tidak sehat sehingga berpotensi untuk menjadi pelaku bullying pada saat remaja (Reisen, Viana, \& Neto, 2019). Pengalaman masa anakanak yang buruk dapat menyebabkan gangguan fungsional yang signifikan sehingga menjadi salahsatu faktor resiko melakukan kekerasan di masa remaja (Duke, Pettingell, McMorris, \& Borowsky, 2010).

\section{Lingkungan sekolah}

Faktor berikutnya yang mempengaruhi bullying adalah lingkungan sekolah. penelitian Rezapour, Khanjani dan Mirzai (2019) menemukan bahwa lingkungan sekolah yang nyaman berkaitan dengan bullying verbal, bullying relasional dan cyber bullying yang lebih rendah, sedangkan lingkungan sekolah yang tidak nyaman dan banyak gangguan berkaitan dengan bullying verbal dan bullying relasional yang lebih tinggi. Selain itu, aturan, kenyamanan fisik, keterlibatan, serta dukungan lingkungan juga berkaitan dengan perilaku bullying. Tipe dan kualitas sekolah juga diasosiasikan dengan resiko perilaku bullying (Bevilacqua, et.al, 2016).

\section{PEMBAHASAN}

Berdasarkan telaah pustaka yang dilakukan pada 10 artikel semuanya melakukan penelitian terhadap siswa, sehingga diketahui bahwa perilaku bullying sebagian besar terjadi pada siswa sekolah dengan rentang usia 12-16 tahun. Tempat dilakukannya penelitian juga bervariasi yakni di italy, brazil, iran, inggris, amerika, swedia, hal tersebut memperkuat hasil survey-survey sebelumnya yang menyatakan bahwa perilaku bullying terjadi hampir disemua negara di dunia serta menjadi masalah di dunia pendidikan secara global. Secara spesifik penelitian mengenai bullying dalam 10 artikel yang direview melakukan penelitiannya di sekolah, meskipun penelitian lain sudah mulai meneliti bullying di 
Jurnal Psikologi Terapan dan Pendidikan

ISSN: $2715-2456$

Vol. 1, No. 2, November 2019, pp. 99-107

berbagai tempat, misalnya di tempat kerja (workplace bullying) (Strandmark, Rahm, Rystedt, Nordström, \& Wilde-Larsson, 2018; Fontes, Alarcão, Santana, Pelloso, \& de Barros, 2018; Paciello, Fida, Tramontano, Ghezzi, \& Barbaranelli, 2019), dan di rumah (sibling bullying) (Dantchev, \& Wolke, 2019; Bouchard, Plamondon, \& Lachance2018; Walters, Farley, Deater-Deckard, \& Kim, 2019).

Skala bullying yang digunakan dalam 10 artikel yang di review berbeda-beda, namun secara umum skala yang digunakan berdasarkan pada skala bullying dari Olweous (1993) yaitu pada penelitian penelitian Mazzone dan Camodeca (2019), Charalampous, Demetriou, Tricha, Ioannou, Georgiou, Nikiforou, dan Stavrinides (2018), Thronberg dan Jungert (2017). Penelitian Reisen, Viana, dan Neto, (2019) menggunakan instrumen yang dibuat oleh fischer (2010) namun tetap didasarkan pada Olweous bully questionare. Sementara itu, penelitian Murphy, Laible, dan Augustine (2017) menggunakan The Participant Role Questionnaire yang dikembangkan oleh Salmivali (1996).

Ditemukan empat faktor utama yang mempengaruhi bullying yaitu faktor kepribadian (Mitsopoulo \& giovazolias, 2015; Thronberg \& Jungert, 2017; Mazzone \& Camodeca, 2019), keluarga Charalampous, Demetriou, Tricha, Ioannou, Georgiou, Nikiforou, \& Stavrinides, 2018; Mazzone \& Camodeca, 2019)., Adverse children experience (Reisen, Viana, \& Neto, 2019), dan lingkungan sekolah (Bevilacqua, et.al, 2016; Rezapour, Khanjani dan Mirzai, 2019).

Keterbatasan dalam penelitian ini adalah minimnya database journal yang diakses oleh peneliti, serta pembahasan mengenai bullying hanya pada bullying di area sekolah, sehingga penelitian ini belum menggambarkan faktor-faktor bullying di area tempat kerja dan di rumah. Bagi penelitian selanjutnya, sebaiknya meneliti faktor-faktor bullying secara keseluruhan baik itu di sekolah, di rumah dan di tempat kerja.

\section{KESIMPULAN}

Hasil studi literatur menunjukan bahwa faktor-faktor yang mempengaruhi bullying adalah faktor kepribadian, faktor keluarga, faktor pengalaman di masa kecil dan faktor lingkungan sekolah.

\section{DAFTAR PUSTAKA}

Abdussalam, M. S. (2018, July 27). 8 dari 10 anak Indonesia pernah di bully, harus segera di akhiri karena bisa bunuh diri. jabar.tribunnews.com. http://jabar.tribunnews.com/2018/07/27/8-dari-10anak-indonesia-pernah-di-bully-harus-segera-diakhiri-karena-bisa-bunuh-diri.

Ayu, I. S., \& Rahayu, K. I. (2014). Hubungan antara tindakan bullying dengan prestasi belajar anak korban bullying. Jurnal Psikologi Udayana, 1, 251-260.

Ba, Z., Han, Z., Gong, Z., Li, F., Zhang, H., \& Zhang, G. (2019). Ethnic differences in experiences of school bullying in China. Children and Youth Services Review, 104402. Doi:10.1016/j.childyouth.2019.104402 
Bevilacqua, L., Hale, D., Shackleton, N., Allen, E., Bond, L., Christie, D., ... Viner, R. (2016). The role of school context and family factors in bullying and cyberbullying. Archives of Disease in Childhood, 1(1), 51-55. Doi:10.1136/archdischild-2016-310863.90

Bostari, E. M., \& Karagianni. (2014). Cyberbullying in Greek adolescent: The role of parents. ProcesiaSocial and Behavior Sciences, 116, 3241-3253.

Bouchard, G., Plamondon, A., \& Lachance-Grzela, M. (2018). Parental intervention style and adult sibling conflicts. Journal of Social and Personal Relationships, 026540751879322. doi:10.1177/0265407518793227

Bruyn, E. H., Cillessen, A. H. N., \& Wissink, I. B. (2010). Associations of peer acceptance and perceived popularity with bullying and victimization in early adolescence. The Journal of Early Adolescence, 3, 543-566. https://doi.org/10.1177/0272431609340517

Careera, V. M., DePalma, R., \& Lamerias, M. (2011). Toward a more comprehensive understanding bullying in school setting. Educational Psychology Review, 23(4), 479-499. http://dx.doi.org/10.1007/s10648-011-9171-x.

Charalampous, K., Demetriou, C., Tricha, L., Ioannou, M., Georgiou, S., Nikiforou, M., \& Stavrinides, P. (2018). The effect of parental style on bullying and cyber bullying behaviors and the mediating role of peer attachment relationships: A longitudinal study. Journal of Adolescence, 64, 109-123. doi:10.1016/j.adolescence.2018.02.003

Dantchev, S., \& Wolke, D. (2019). Trouble in the nest: Antecedents of sibling bullying victimization and perpetration. Developmental Psychology, 55(5), 1059-1071. http://dx.doi.org/10.1037/dev0000700

Duke, N. N., Pettingell, S. L., McMorris, B. J., \& Borowsky, I. W. (2010). Adolescent Violence Perpetration: Associations with Multiple Types of Adverse Childhood Experiences. Pediatrics, 125(4), e778-e786. Doi:10.1542/peds.2009-0597

Evans, C. B. R., Smokowski, P. R., Rose, R. A., Mercado, M. C., \& Marshal, K. J. (2018). Cumulative bullying experiences, adolescent behavioral and mental health, and academic achievement: an integrative model of perpetration, victimization, and bystander behavior. Journal of Child and Family Studies, 1-14. Doi: 10.1007/s10826-018-1078-4.

Fanti, K. A., Frick, P. J., \& Georgiou, S. (2008). Linking Callous-Unemotional Traits to Instrumental and Non-Instrumental Forms of Aggression. Journal of Psychopathology and Behavioral Assessment, 31(4), 285-298. Doi:10.1007/s10862-008-91

Farrington, D. P., \& Ttofi, M. (2011). Bullying as a predictor of offending, violence, and later life outcomes. Criminal Behaviour and Mental Health, 21(2), 90-98. https://doi.org/10.1002/cbm.801.

Fousiani, K., Michaelides, M., \& Dimitropoulou, P. (2018). The effects of ethnic group membership on bullying at school: when do observers dehumanize bullies?. The Journal of Social Psychology, 112. Doi:10.1080/00224545.2018.1505709

Garandeau, C. F., Lee, I. A., \& Salmivalli, C. (2013). Inequality Matters: Classroom Status Hierarchy and Adolescents' Bullying. Journal of Youth and Adolescence, 43(7), 1123-1133. doi:10.1007/s10964-013-0040-4

Georgiou, S. N., Stavrinides, P., \& Fousiani, K. (2013). Authoritarian Parenting, Power Distance, and Bullying Propensity. International Journal of School \& Educational Psychology, 1(3), 199-206. Doi:10.1080/21683603.2013.806234

Hawley, P. H. (2003). Prosocial and coercive configurations ofresource control in early adolescence: A case for the well-adaptedMachiavellian. Merrill-Palmer Quarterly, 49(3), 279309.https://doi.org/10.1353/mpq.2003.0013.

Healy, K. L., Sanders, M. R., \& Lyer, A. (2015). Parenting practices, children's peer relationships and being bullied at school. Journal of Child and Family Study, 24, 127-140, Doi: 10.1007/s10826013-9820-4 
Mazzone, A., \& Camodeca, M. (2019). Bullying and Moral Disengagement in Early Adolescence: Do Personality and Family Functioning Matter?. Journal of Child and Family Studies. Doi:10.1007/s10826-019-01431-7

Menesini, E., Nocentini, A., \& Camodeca, M. (2011). Morality, values, traditional bullying, and cyberbullying in adolescence. British Journal of Developmental Psychology, 31(1), 1-14. Doi:10.1111/j.2044-835x.2011.02066.x

Mitsopoulou, E., \& Giovazolias, T. (2015). Personality traits, empathy and bullying behavior: A metaanalytic approach. Aggression and Violent Behavior, 21, 61-72. Doi:10.1016/j.avb.2015.01.007

Murphy, T. P., Laible, D., \& Augustine, M. (2017). The Influences of Parent and Peer Attachment on Bullying. Journal of Child and Family Studies, 26(5), 1388-1397. Doi:10.1007/s10826-0170663-2

New SGD 4 Data on Bullying. (2018, Oktober 01). http://uis.unesco.org/en/news/new-sdg-4-databullying

Nuridha, L. (2017, November 3). Kasus bullying meningkat, perilaku di dominasi oleh remaja. https://kumparan.com/@kumparanstyle/kasus-bullying-meningkat-pelaku-didominasi-olehremaja.

Nurlita, D., \& Widiastuti, R. (2018, July 23). Hari anak nasional, KPAI catat kasus bullying paling banyak. https://nasional.tempo.co/read/1109584/hari-anak-nasional-kpai-catat-kasus-bullyingpaling-banyak.

Octavianto, M. R. (2017). Perilaku bullying di sekolah menengah atas kota Yogyakarta. Jurnal Riset Mahasiswa Bimbingan dan Konseling, 3 (8), 376-386. http://journal.student.uny.ac.id/ojs/index.php/fipbk/article/viewFile/8417/8018.

Olweus, D. (1993). Bullying at school: What we know and what we can do. Victoria: Blackwell Publishing

Paciello, M., Fida, R., Tramontano, C., Ghezzi, V., \& Barbaranelli, C. (2019). Phenomenological configurations of workplace bullying: A cluster approach. Personality and Individual Differences. Doi:10.1016/j.paid.2019.05.001

Reisen, A., Viana, M. C., \& dos Santos Neto, E. T. (2019). Adverse childhood experiences and bullying in late adolescence in a metropolitan region of Brazil. Child Abuse \& Neglect, 92, 146-156. Doi:10.1016/j.chiabu.2019.04.003

Rezapour, M., Khanjani, N., \& Mirzai, M. (2019). Exploring associations between school environment and bullying in Iran: Multilevel contextual effects modeling. Children and Youth Services Review, 99, 54-63. Doi:10.1016/j.childyouth.2019.01.036

Smokowski, P. R., \& Kopasz, K. H. (2005). Bullying in school: An overview of types, effects. National Association of Social Workes, 27(2), 101-110. ISSN-1532-8759.

Strandmark K., M., Rahm, G., Rystedt, I., Nordström, G., \& Wilde-Larsson, B. (2018). Managing bullying in Swedish workplace settings: A concealed and only partially acknowledged problem. Journal of Nursing Management. Doi:10.1111/jonm.12668

Su, Q., Chen, Z., Li, R., Elgar, F. J., Liu, Z., \& Lian, Q. (2018). Association Between Early Menarche and School Bullying. Journal of Adolescent Health, 63(2), 213-218. Doi:10.1016/j.jadohealth.2018.02.008

Sung, J. H., Dorothy, E. L., Kaylor, E., \& Allen, P. M. (2011). Identifying potential mediators and moderators of the association between child maltreatment and bullying perpetration and victimization in school. Educational Pdychologi Review, 24, 167-186. http://dx.doi.org/10.1007/s10648-011-9185-4.

Thornberg, R., \& Jungert, T. (2017). Callous-Unemotional Traits, Harm-Effect Moral Reasoning, and Bullying Among Swedish Children. Child \& Youth Care Forum, 46(4), 559-575. Doi:10.1007/s10566-017-9395-0 
Jurnal Psikologi Terapan dan Pendidikan

ISSN: $2715-2456$

Vol. 1, No. 2, November 2019, pp. 99-107

Turunen, T., Poskiparta, E., \& Salmivalli, C. (2017). Are reading difficulties associated with bullying involvement?. Learning and Instruction, 52, 130-138. Doi:10.1016/j.learninstruc.2017.05.007

Walters, J. M., Farley, J. P., Deater-Deckard, K., \& Kim-Spoon, J. (2019). Predictors of Sibling Victimization and Associations with Self-Perception and Relationship Attachment in Adolescence. The Journal of Early Adolescence, 027243161983738. Doi:10.1177/0272431619837382

Wilford, A., Bouton, A. J., Bank, S. S. F., Bender, K. A., Dieterich, W. A., \& Jenson, J. M. (2015). The effect of bullying and victimization on cognitive empathy development during the transition to middle school. Child Youth Care Forum. Doi: 10.1007/s10566-015-9343-9.

Zhou, Y., Guo, L., Lu, C., Deng, J., He, Y., Huang, J., ... Gao, X. (2015). Bullying as a Risk for Poor Sleep Quality among High School Students in China. Plos one, 10(3), e0121602. Doi:10.1371/journal.pone.0121602 